\title{
REFORMAS NEOLIBERAIS E POLÍTICAS PÚBLICAS: HEGEMONIA IDEOLÓGICA E REDEFINIÇÃO DAS RELAÇÕES ESTADO-SOCIEDADE
}

\begin{abstract}
RESUMO: A narrativa neoliberal - produção de idéias, imagens, valores - descreve e pretende explicar os supostos despautérios do mundo social "regulado politicamente". Para a reforma dos serviços públicos, como se sabe, aponta a supremacia do mercado como mecanismo alocador de recursos (eficiência) e também como gerador de justiça, igualdade, liberdade. Desenha a iminência do apocalipse para insinuar propostas salvacionistas. As demais visões do mundo são acusadas de caudatárias de "interesses especiais", estratégia de um populismo de novo tipo, que faz a guerra contra o Estado... com base nos poderes de Estado. A conquista da hegemonia neoliberal não se mede pelo sucesso em indicadores convencionais (crescimento econômico, bem-estar social). Também não significa apenas nem principalmente definir as respostas certas aos problemas, mas definir quais são os problemas certos e os termos em que devem ser equacionados. Seu alvo é modificar drasticamente os temas e valores compartilhados, de modo que se enquadrem as eventuais alternativas no terreno pejorativo do impensável e se alterem em profundidade os espaços e processos em que se fazem as escolhas sociais relevantes.
\end{abstract}

Reginaldo C. Moraes

Palavras-chave: Neoliberalismo. Políticas públicas. Hegemonia. Democracia. Ideologia.

NEOLIBERAL REFORMS AND PUBLIC POLICIES - IDEOLOGICAL HEGEMONY AND THE REDEFINITION OF THE STATE-SOCIETY RELATIONSHIPS ABSTRACT: The neoliberal narrative - production of ideas, images, values - describes and intends to explain the supposed nonsense of the social world "politically regulated". For a reformation of public services, it pinpoints the supremacy of market as a mechanism that grants resources (efficiency) as well as it generates justice, equity and liberty. It outlines the imminence of doom to better convey messianic

* Professor da Faculdade de Educação da UNICAMP. E-mail: remoraes@terra.com.br

Educ. Soc., Campinas, v. 23, n. 80, setembro/2002, p. 13-24

Disponível em <http://www.cedes.unicamp.br> 
proposals. Under this scope, the other visions of the world are accused of being subservient to "special interests" or of representing a new kind of populist strategy at war with the State... using the very powers of the State. Conventional indicators (economical growth, social welfare) cannot detect the neoliberal conquest of hegemony. Besides, such narrative does not mean only, or mainly, defining the right answers to the problems, but which are the right problems and in which terms they should be addressed. Its purpose is both to modify drastically the shared topics and values so that any possible alternative be relegated to the depreciatory ground of the unthinkable and to deeply reshape the spaces and processes in which relevant social choices are made.

Keywords: Neoliberalism. Public policies. Hegemony. Democracy. Ideology.

7 ação política, como se sabe, é exercida por meio de vários instrumentos. E um deles, nem sempre devidamente considerado, é a produção e difusão de idéias, imagens, valores. Dizer que algo é "apenas um discurso" ou "mero reflexo" pode ser perigoso, porque arrisca ignorar que enunciados são armas.

Ora, aquilo que se tem chamado de pensamento único ou hegemonia ideológica neoliberal teve como uma de suas armas mais efetivas precisamente a capacidade de gerar e difundir narrativas que prometiam explicar o mundo em crise dos anos 70 , quais sejam:

- a falência do regime monetário acordado na famosa conferência de Bretton Woods (1944);

- o esgotamento dos modelos de acumulação de capital do pósguerra e das instituições políticas que lhe eram afins (em especial a democracia de massas);

- e a inviabilidade das políticas nacionais voltadas para: promover o desenvolvimento econômico; controlar os ciclos de crescimento e recessão; gerir eficientemente as relações interclasses (as políticas de renda e de bem-estar social, em particular).

Em outros termos, as narrativas neoliberais pretenderam - e em certa medida conseguiram - oferecer explicação palatável para a crise e alternativa plausível para a superação daquilo que se usou chamar de consenso keynesiano dos "trinta gloriosos" do pós-guerra. ${ }^{1}$

Uma dessas narrativas - talvez uma das mais bem-sucedidas, no sentido de operar como instrumento de coesão social e imposição das 
idéias dominantes - é aquela que explica os problemas derivados das políticas sociais ou do Estado de Bem-Estar Social. ${ }^{2}$ Nessa estória, três scripts correm em paralelo, conectando-se em circunstâncias apropriadas:

- os custos crescentes (e tendencialmente insuportáveis) das políticas sociais e seu impacto sobre os fundos públicos (inflação, endividamento);

- os efeitos deletérios dessas políticas sobre valores, comportamentos de indivíduos, grupos sociais e empresas;

- os resultados desastrosos, sobre o processo decisório e sobre as instituições democráticas, da maquinaria política exigida pela implementação desses programas.

Graças à peculiar combinação desses scripts, conseguiram unirse, nas últimas décadas do século XX, em especial, duas correntes ideológicas que durante longo tempo haviam permanecido em campos separados (e muitas vezes opostos): o fundamentalismo de mercado - com sua crença (paradoxal) nas virtudes criadoras da destruição das tradições ${ }^{3}$ - e o conservadorismo, por sua vez defensor exatamente das tradiçôes e da autoridade estabelecida. ${ }^{4}$

O neoliberalismo econômico acentua a supremacia do mercado como mecanismo de alocação de recursos, distribuição de bens, serviços e rendas, remunerador dos empenhos e engenhos inclusive. Nesse imaginário, o mercado é matriz da riqueza, da eficiência e da justiça.

A intervenção da autoridade pública sobre as iniciativas privadas é vista, primordialmente, como intrusão indevida, no máximo tolerada. Dela só podem resultar distorções naqueles três eixos mencionados (riqueza, eficiência, justiça). Quando o Estado intervém sobre os criativos empreendedores, para supostamente preservar o bem público (as regulaçôes legais) ou sustentar suas atividades (a taxação), inibe aquilo que é mola propulsora do progresso e afeta a competitividade dos agentes. É usual substituir o termo "taxação excessiva" por termos mais duros - taxação confiscatória, escorchante, sufocante. Esses termos são preferidos, nas mensagens que buscam popularizar a doutrina, uma vez que apelam, silenciosamente, à metáfora vital da respiração e à referência, sibilina, ao crime. As regulaçôes estatais também distorcem o comportamento das empresas - estas desviam recursos das atividades produtivas "sadias" para atividades improdutivas - destinadas a influir, de modo legal, semilegal ou mesmo ilegal, sobre as instituiçôes reguladoras, que buscam "colonizar". ${ }^{5} \mathrm{O}$ Estado também distorce o belo mundo dos mercados ao proteger desarrazoadamente os direitos 
do trabalho - nas suas condições ou na sua remuneração - ou ainda quando cria instituições que "desmercadorizam" parte dos elementos necessários à sobrevivência da escravaria assalariada (educação, saúde, previdência, seguro-desemprego, moradia, transportes, sabe-se lá mais o quê!). Desse modo, além de pressionar os bolsos dos ricos (que assim se vêem impedidos de investir), gera "desincentivos" ao trabalho, induzindo ao comportamento, digamos, preguiçoso ou aproveitador, "encostado". No fabulário liberal, o cidadão divide-se em um Dr. Jeckil e um Mr. Hyde: por um lado, contibuinte suado, esfolado para pagar taxas escorchantes; por outro, aproveitador, sempre à espretia de um free lunch, comportando-se, afinal, como o malandro de Noel Rosa, para quem "mais vale almoçar na casa de um parente do que trabalhar para ganhar o insuficiente". Daí, sociólogos, economistas e cientistas políticos dos think tanks neoliberais se esmeraram em demonstrar que o "sufocamento" do "homem econômico racional" por instituições assistenciais excessivas conduziria a incentivos perversos, como a poverty trap.

\section{Profetas do apocalipse}

Como seria de esperar, a vertente neoconservadora do pensamento único, requentando temas de Burke e Spencer, acentuará esses efeitos deletérios sobre o comportamento moral: alguns dos descendentes do velho Adão teriam arranjado um meio de contornar a sina de ganhar a vida com o suor do próprio rosto, ${ }^{6}$ transformando-se em "caronistas" do gasto público, free-riders. Ao invés de indivíduos independentes, empreendedores, autoconfiantes, teríamos dependentes químicos do welfare-state. Ao invés de famílias, teríamos hordas de mães solteiras ou abandonadas e pais prolíficos no esperma, mas estéreis na responsabilidade. Não estaríamos muito longe, no século XX, do destino de Sodoma e Gomorra. Para quem pense que estou exagerando, sugiro a leitura dos sermões de James Buchanan, ganhador do Prêmio Nobel de Economia em 1986. Veja por exemplo as seguintes passagens:

Durante varias décadas (...) nossa ordem moral tem estado num processo de erosão. Um número cada vez maior de pessoas parece se tornar anarquistas morais; parece estar perdendo um senso de respeito mútuo uns pelos outros, juntamente com qualquer propensão a comportar-se segundo regras e códigos de conduta generalizáveis. (Buchanan, 1986)

(...) (tem-se observado) erosão generalizada na conduta pública e privada, atitudes crescentemente liberalizadas no que diz respeito a atividades sexuais, uma vitalidade declinante da ética puritana do trabalho, deterioração na 
qualidade dos produtos (...), corrupção difundida tanto no setor governamental quanto no privado, e, finalmente, aumentos perceptíveis na alienação dos eleitores diante do processo político. (Buchanan \& Wagner, 1977)

Esta última passagem, aliás, figura em livro cujo título Democracy in deficit: the political legacy of Lord Keynes - nomeia quase tudo que a demonologia neoliberal pretende exorcizar: a democracia de massas, inapelavelmente ingovernável, porque sobrecarregada e condenada a "operar no vermelho", e a macroeconomia keynesiana, voltada a objetivos insanos (controle dos ciclos, manutenção de pleno emprego etc.) e destruidora das virtudes disciplinadoras do mercado. Diante desta catástrofe - já não iminente, mas efetivamente produzida - receitam-se as reformas constitucionais que imponham limites às instituições democráticas e ao Estado de bem-estar:

(...) tendo vivido a destruição da moralidade fiscal pelo aparato intelectual keynesiano, devemos fazer todos os esforços para substituir esta moralidade por restrições deliberadamente escolhidas que produziriam substancialmente os padrões pré-keynesianos de resultados. (Buchanan \& Wagner, 1977)

São "remédios amargos" e, a julgar pelas inclinações de nossos virtuosos e abnegados pregadores, ainda mais saudáveis porque mais amargos. Contudo, por amargos, são pouco simpáticos ao doente. $\mathrm{O}$ que fazer?

A solução ideal seria o retorno a uma ética de orçamento equilibrado, com a violação dessa ética levando a sanções tanto internas quanto externas sobre os malfeitores políticos. Uma vez erodido um padrão ético, contudo, é difícil reabilitá-lo, pelo menos no nível ético. Isto sugere a desejabilidade de impor um limite explícito sobre o processo político que requeira equiparação de gastos com rendas originárias de taxas exceto sob circunstâncias excepcionais. Não há razão para esperar que políticos venham a impor tal limite sobre si mesmos, ou que isso fosse mantido muito tempo, mesmo se imposto. Dada a situação fiscal em que agora nos encontramos, significativo limite sobre a política orçamentária terá de ser imposto num nível que transcende a política ordinária. Uma emenda de equilíbrio orçamentário à Constituição não será nem tão abrangente ou tão efetiva quanto idealmente desejaríamos, mas dadas as reais e urgentes alternativas, tal emenda tem muito a recomendá-la. (Lee, 1977, p. 306)

Em alguns países, como se sabe, o "nível que transcende a política ordinária” implicou caminhos muito especiais. Os governos 
dos generais Pinochet (Chile, 1973) e Videla (Argentina, 1976) enquadram-se nesse nível transcendente e foram assessorados, diretamente, pelos economistas da escola de economia da Universidade de Chicago. ${ }^{7}$

Constitui um grande mérito literário da Nova Direita ter conseguido conectar todos esses elementos ideológicos, não necessariamente integráveis, em um discurso razoavelmente persuasivo. Assim, conseguiu ir além da denúncia "econômica" ou "fiscal" das políticas sociais, o que arriscaria preservá-las como "coisas boas, mas impossíveis de sustentar". Com o enfoque da Nova direita, elas aparecem, mais e melhor, como sintomas de decadência civilizacional e, simultânea e paradoxalmente, como indutoras da decadência. Como algo intrinsecamente mau e que não se deve sustentar, mesmo quando possível fazê-lo.

A crítica do Estado de bem-estar social - ou das políticas públicas, em geral - teve que ensaiar várias linhas de ataque. Vejamos a imagem que se desenha do servidor público. Procura-se mostrar que seu apego a regras e impessoalidade - valores positivos da burocracia, na argumentação weberiana - conduz de modo inevitável (e independente das instituiçōes de controle popular) a traços perversos: burocratismo, desprezo pelos resultados (o bem público, afinal), tratamento despótico e auto-suficiente diante do cidadão comum, busca incessante de mais poder (e portanto mais orçamentos...), insulamento ante a cobrança de desempenho (que "por exemplo" está suposta na competição de mercado).

Soma-se a estas escaramuças o ataque a diferentes manifestaçōes da democracia representativa, com particular ênfase nos legislativos e nos governos subnacionais, apontados, com freqüência, como ralos por onde mais facilmente escoam a racionalidade e a responsabilidade fiscal. Curiosamente, esta desqualificação vem junto com políticas de suposta descentralização de operaçôes do Estado. Mas não se junta, e esse é um detalhe significativo, à descentralização do poder normativo, isto é, das prerrogativas de formular regras paramétricas das políticas públicas, incluindo, é claro, as práticas de avaliação de desempenho e distribuição dos grandes fundos públicos. ${ }^{8}$

\section{A guerra contra o Estado - a partir de quem detém o poder...}

As narrativas da Nova Direita estavam voltadas para demolir um consenso e substituí-lo por outro. Para isso, as idéias prece- 
dentes - ou todas aquelas exteriores ao novo dogma - tinham que ser apresentadas como contra-senso, manifestação de interesses corporativos e/ou particularistas, sobrevivências de doutrinas antiquadas. Como lembrava a ironia de um pensador oitocentista, preconceitos são... as idéias dos outros. As nossas são ciência, bom senso, interesse geral. ${ }^{9}$

Paradoxalmente, a guerra contra o Estado teria que ser feita por grupos e partidos que se perpetuavam no comando desse mesmo Estado. $\mathrm{Na}$ América Latina e no Brasil, em especial, a estória resvalava pelo perigoso terreno da galhofa. Os vícios "estatistas" - com seus corolários como inflação e endividamento - eram assimilados ao esquerdismo ideológico... em países em que ditaduras de direita governavam por décadas, ou desde quando a memória pode captar.

O antiestatismo da Nova Direita, na verdade, não leva a qualquer forma de anarquismo tresloucado. Leva a propostas de reforma do Estado, por intermédio das quais suas agências são supostamente "profissionalizadas" e "despolitizadas" por meio de um enfoque "gerencial", voltado para o "cliente", para os "resultados", para a "qualidade do output" e não para a fidelidade a normas. Não se trata apenas de uma reforma administrativa, repare-se. Nem, muito menos, de uma proposta de "abrir" o Estado para os olhos e para as falas dos cidadãos - conseqüência normativa (progressista) que também poderia ser extraída de uma análise crítica do big government do pós-guerra. ${ }^{10}$ Pelo contrário, trata-se de uma libertação da máquina do Estado do universo alegadamente volúvel, incerto e destemperado da democracia representativa. A Nova Direita, em seus mais prolíficos e sofisticados ideólogos, como os da chamada escola da Public Choice, retoma a ofensiva "desemancipadora" dos velhos liberais do século XIX, na sua luta contra a entrada das massas na vida política, por intermédio dos sindicatos, dos partidos ou do sufrágio. ${ }^{11}$ A Nova Direita tem consciência de que o Estado de bemestar ou as políticas sociais não eram apenas uma "administração", mas um modelo civilizacional. Eram um modo de conexão, de representação de vontades e interesses, já que suas políticas precisavam "encarnar" em agências do Estado (secretarias, departamentos, comissões etc.) em que se tomavam deliberaçôes para implementálas. E envolviam diferentes níveis de responsabilidade de governo (federal, estadual, local). É isso que a Nova Direita quer demolir. Sua pergunta fundamental não é o "como", mas o "quê". Sua luta ideológica - a operação que visa a transfigurar valores da parte social 
que representa e/ou idolatra em valores supostamente universais pretende colocar em questão mais do que os caminhos para o progresso, mas a própria definição desse progresso, seu ponto de chegada.

A proposta neoliberal de "reforma" dos serviços públicos, como se sabe, é orientada por uma idéia reguladora: a idéia de privatizar, isto é, de acentuar o primado e a superioridade da ratio privada sobre as deliberações coletivas. Daí suas diferentes maneiras de manifestação. Privatizar, no sentido estrito do termo, é apenas uma delas: transferir a agentes privados (empresas) a propriedade e gestão de entes públicos. Mas há outros modos de fazer valer o mandamento. Pode-se delegar a gestão, sem necessariamente transferir a propriedade. Pode-se ainda manter na esfera estatal a gestão e a propriedade, mas providenciando reformas que façam funcionar os agentes públicos "como se" estivessem no mercado, modelando o espaço público pelos padrões do privado. Diferentes modos de descentralização e dispersão de operações - com a correspondente centralização e o insulamento dos âmbitos de definição das grandes políticas, das práticas de avaliação de desempenho, de distribuição do bolo orçamentário - são pensadas como formas de introduzir o ethos privado (dinâmico, purificador) do mercado no reino das funções públicas. ${ }^{12}$

Hegemonia e a arte de definir os termos da disputa

Veja-se portanto que as reformas neoliberais não visam apenas a acertar balanços e cortar custos - garantindo o sagrado superávit primário, imprescindível à remuneração dos juros da dívida (interna e externa). Trata-se de mudar a agenda do país. De modificar drasticamente os temas e valores compartilhados, de modo que se enquadrem as eventuais alternativas no terreno pejorativo do impensável. E de alterar em profundidade os espaços e processos em que se faz política, isto é, em que se fazem escolhas relevantes. Mesmo quando essas deliberaçóes sejam "públicas” - já que não se pode lançá-las, infelizmente, às decisões (supostamente) descentralizadas do mercado -, que esse espaço seja cada vez mais parecido com o seu senhor, modelo e telos, isto é... com o mercado. As reformas neoliberais têm como horizonte (e, portanto, como critério de avaliação de seus sucessos) a prerrogativa de definir os termos e os parâmetros do que é "racional".

Por isso, os projetos neoliberais não devem ser desligados de uma antiga preocupação dos ideólogos da chamada Comissão Trilateral, 
em meados dos anos 70, justamente quando o modelo de Bretton Woods fazia água. Naquele momento, a crítica de esquerda acentuava os conflitos entre capitalismo e democracia, colocando o peso da dívida sobre o primeiro termo. ${ }^{13}$ A direita retoma o dilema a seu modo, apontando a democracia como culpada dos males. O tema da ingovernabilidade das democracias entrava com pompa na agenda da political science tida como respeitável. ${ }^{14}$ Não apenas continua na cena, hoje, mas tem mesmo determinado, delimitado e pautado, com notável desenvoltura, o discurso de muitos de seus antigos opositores, que se candidatam a segundas chances ao desvendar supostas terceiras vias. Como outros dogmas silenciosamente legitimados pela vaga neoliberal, o tema da (in)governabilidade tem a força dos mitos que, conforme lembra Fernando Pessoa, nos dirigem sem que o saibamos:

O mito é o nada que é tudo.

...

Este, que aqui aportou,

Foi por não ser existindo.

Sem existir nos bastou.

Por não ter vindo foi vindo

E nos criou.

Assim a lenda se escorre

A entrar na realidade,

E a fecundá-la decorre.

Embaixo, a vida, metade

De nada, morre.

Recebido e aprovado em julho de 2002.

\section{Notas}

1. Para um exame do idéario neoliberal, de suas origens e correntes, tomo a liberdade de remeter o leitor a meu livro (Moraes, 2001).

2. Vale enfatizar essa "verdade" da narrativa. Ela não deriva de qualquer suposta adequatio entre coisa e idéia, realismo de pressupostos ou potencial de predição de fatos independentes dos seus enunciados. A verdade da doutrina deriva da efetividade desses enunciados, da sua capacidade de "virar fato" em virtude de conquistarem a imaginação dos sujeitos-objetos, isto é, dos agentes que examina e cujo comportamento ao mesmo tempo explica e dirige. Merton, em brilhante ensaio a respeito das profecias que se auto-realizam, já mostrara esse peculiar sentido da verdade nos fatos sociais, explorando

Educ. Soc., Campinas, v. 23, n. 80, setembro/2002, p. 13-24 
a frase de W. I. Thomas: "Se os indvíduos definem as situações como reais, elas são reais em suas conseqüências" (Merton, 1970).

3. Vale citar, entre tantas passagens, estas linhas de um escritor antiquado: "Essa revolução contínua da produção, esse abalo constante de todo o sistema social, essa agitação permanente e essa falta de segurança distinguem a época burguesa de todas as precedentes. Dissolvem-se todas as relações sociais antigas e cristalizadas, com seu cortejo de concepções e de idéias secularmente veneradas; as relações que as substituem tornam-se antiquadas antes de se ossificar. Tudo que era sólido e estável se esfuma, tudo o que era sagrado é profanado..." (Manifesto Comunista, 1948).

4. Essas duas vertentes e suas dificuldades de coexistência (quanto mais de colaboração) são examinadas, para a Nova Direita norte-americana, por um importante livro de George Nash (1996).

5. Anne Krueger, ex-economista-chefe do Banco Mundial e hoje alta dirigente do FMI, cunhou para esse fenômeno uma expressão que foi depois celebrizada: a "rent-seeking society" - a sociedade de predadores em que todos perdem. Segundo essa doutrina, o intervencionismo estatal propicia "situaçôes de renda", ou seja, posiçôes na sociedade que permitem a um agente (indivíduo, empresa, grupo) capturar vantagens (rendas) superiores àquelas que obteria no mercado, no reino dos preços e "custos de oportunidade". São, em suma, vantagens de posição favorecidas por artifícios legais. Daí decorrem dois males, ou perversões: esses agentes investem seus esforços e recursos mais na busca predatória de privilégios do que na de aumentar o produto global; os "tomadores de decisão", na administração pública, são "ofertadores de rendas", isto é, empregos ou legislação, em troca de benefícios monetários (corrupção) ou apoio político. Cf. Krueger (1974, 1980). Jagdish Bhagwati transformou esse modelo em um mais amplo, o das "Directly Unproductive, Profit-Seeking (DUP) activities" (Bhagwati, 1982).

6. A metáfora, como se sabe, pertence a Marx. Mas os sujeitos indicados são bem outros.

7. Para o caso do Chile, há detalhado e documentado estudo de Juan Gabriel Valdés (1995). Para a Argentina, cf. Vadel, 1997.

8. Para um exame mais detalhado dos programas de reformas neoliberais no campo das políticas sociais, remeto a meu artigo: "As incomparáveis virtudes do mercado: Políticas sociais e padrōes de atuação do Estado nos marcos do neoliberalismo” (Moraes, 2000).

9. Com um misto de prazer e horror próprios de pregadores em transe, os apologistas da Nova Direita costumam enumerar aqueles grupos de interesse, particularistas, que disputam encarniçadamente o butim estatal, canibalizando-o e esterilizando o processo decisório. $\mathrm{O}$ leitor mais frio, contudo, ficaria intrigado: são tribos de negros, latinos, mulheres, incapazes, filhos sem mãe... Somados, enfim, resumem quase tudo o que existe na sociedade. Pouco resta fora dessa malta de desclassificados e aproveitadores potenciais. Com certeza, porém, uma tribo fica de fora: os financistas e seus elegantes operadores. Estes talvez se prendam menos a interesses "particularistas" e se voltem para os universais - quem sabe porque vivam no ciberespaço e no reino do equivalente universal...

10. Refiro-me às muitas e variadas reflexões - e experimentos, como os orçamentos participativos - que podem ser listadas na genérica fórmula da "democracia participativa". Reconhecidos seus méritos e potenciais educativos, cabe porém registrar o quanto têm sido limitados, como alternativa abrangente à reforma "gerencial" do Estado em voga.

11. Um instigante e erudito livro sobre o tema é o de Domenico Losurdo, 1993.

12. Um dos corifeus da Nova Direita, James Buchanan, ganhou o Prêmio Nobel de Economia pelas suas contribuições a esse campo. Uma delas é a curiosa teoria econômica dos clubes, um modelo que pretende explicar (e prover meios de gerenciar) as políticas públicas numa sociedade complexa. Remeto a meu artigo (Moraes, 2000) para detalhes do engenho. É

Educ. Soc., Campinas, vol. 23, n. 80, setembro/2002, p. 13-24

Disponível em <http://www.cedes.unicamp.br> 
aliás notável a capacidade de diplomar excêntricos e tarados que encontramos na comissão que administra esse prêmio distintivo da alta ciência. Em 1997, dois economistas norteamericanos, Myron Scholes e Robert Merton (não confundir com o velho sociólogo de Harvard), foram agraciados por terem encontrado uma espécie de versão pós-moderna da Lâmpada de Aladim. Teriam construído um modelo econométrico fantástico, que permitiria tratar, com absoluta segurança, as incertezas do mundo das finanças (as variaçôes dos derivativos, em especial). Munidos do prestígio conferido pelo prêmio e pelo maravilhoso arterfato, transformaram um fundo de aplicaçōes, o Long Term Capital Management, criado em 1991, em Nova Iorque, por um ex-dirigente da corretora Salomon Brothers, em algo que prometia ser à prova de quebras. Depois de um ano, aproximadamente, faliram ruidosamente, obrigando o Banco Central norte-americano (FED) a organizar uma operação de salvamento de cerca de 4 bilhões de dólares...

13. A referência mais direta é para o livro de James O'Connor: The fiscal crisis of the State, de 1973.

14. Deste lado do espectro, a referência, óbvia e famosa, é o relatório da Comissão Trilateral, escrito na mesma época do ensaio de O'Connor e publicado como livro um pouco depois (Crozier, Huntington e Watanuki, 1975).

\section{Referências bibliográficas}

BHAGWATI, J. Directly unproductive, profit-seeking (DUP) activities. Journal of Political Economy, Chicago, n. 90, 1982.

BUCHANAN, J. Liberty, market and state: political economy in the 1980s. Brighton, Sussex: Wheatsheaf books, 1986. p. 116.

BUCHANAN, J.; WAGNER, R. Democracy in deficit: the political legacy of Lord Keynes. London: Academic Press, 1977. p. 65.

CROZIER, M.; HUNTINGTON, S.; WATANUKI, J. The crisis of democracy. New York: New York University, 1975.

KRUEGER, A. The political economy of the Rent-Seeking Society. American Economic Review, Nashville, Tenn., n. 64, 1974. Reeditado na coletânea organizada por: BUCHANAN, J. ; TOLLISON, R.D. ; TULLOCK, G. Toward a theory of the RentSeeking Society. College Station, Texas A\&M Press, 1980.

LEE, D. Deficits, political myopia and the asymmetric dynamics of taxing and spending. In: Buchanan, J. Déficits..., p. 306.

LOSURDO, D. Democracia bonapartismo: trionfo e decadenza del suffragio universale. Torino: Bollati Boringhieri, 1993.

MERTON, R.K. A profecia que se cumpre por si mesma. In: MERTON, R.K Sociologia: teoria e estrutura. São Paulo: Mestre Jou, 1970.

Educ. Soc., Campinas, v. 23, n. 80, setembro/2002, p. 13-24

Disponível em <http://www.cedes.unicamp.br> 
MORAES, R.C. As incomparáveis virtudes do mercado: políticas sociais e padrões de atuação do Estado nos marcos do neoliberalismo. In: Krawczyc, N.; Campos, M.M.; Haddad, S. (Org.). O cenário educacional latino americano no limiar do século XXI: reformas em debate. Campinas: Papirus, 2000.

MORAES, R.C. Neoliberalismo: de onde vem, para onde vai. São Paulo: SENAC, 2001.

NASH, G. The conservative intelectual movement in America (since 1945). Wilmington, Delaware: Intercollegiate Studies Institute, 1996.

O'CONNOR, J. The fiscal crisis of the State. New York, St. Martin's Press, 1973.

VADELL, J.A. Neoliberalismo e consenso na Argentina (1976-1991). 1997. 168f. Dissertação (Mestrado em Ciência Política) - Instituto de Filosofia e Ciências Humanas, Universidade Estadual de Campinas, Campinas.

VALDÉS, J.G. Pinochet's economists: the Chicago School in Chile. Cambridge: Cambridge University, 1995. 334p. 